\title{
A PRIORIDADE ÉTICA DA RETÓRICA PUBLICITÁRIA
}

\author{
Paulo Barroso \\ pbarroso1062@gmail.com \\ Escola Superior de Educação de Viseu, Instituto Politécnico de Viseu \\ 3504-501 Viseu - Portugal
}

\begin{abstract}
Resumo
Qual é a relação entre a publicidade e a moral (esta enquanto objecto da reflexão ética)? A publicidade não depende da moral, mas pode revestir-se de moralidade ou imoralidade. Se a publicidade explora as potencialidades do discurso para se tornar eficaz, é uma forma de retórica ou arte do discurso persuasivo que exige um cuidado ético, pois os fins estão determinados e não justificam os meios. A publicidade assume uma dimensão ética devido às estratégias que utiliza, havendo a possibilidade das estratégias serem ardilosas, falaciosas ou falazes. O tema da ética é, sic et simpliciter, racional, dialéctico e reflexivo. As questões éticas são, por norma, aporéticas. Assim, este texto privilegia uma análise crítica da ética na publicidade e na comunicação. A metodologia traduz-se na problematização e conceptualização da ética da publicidade como uma estética do discurso retórico.
\end{abstract}

\section{Palavras-chave}

Comunicação de massas; ética; publicidade; retórica; secularização

\section{INTRODUÇÃo}

"Não estudamos a ética para saber o que é a ética, mas para nos tornarmos éticos." (Aristóteles, 1992: 1103b26-28).

A supra citação da Ética a Nicómaco, de Aristóteles, pressupõe três aspectos significativos e elementares:

1) As preocupações éticas remontam à Antiguidade Clássica e relacionam-se com a retórica e a política enquanto artes ou saberes técnicos e sociais;

2) O estudo dos fundamentos da acção humana interessa ao conhecimento e à prática social, porque a ética não determina comportamentos ideais, não analisa nem faz juízos de valor, não estabelece as melhores decisões, mas é aplicada, i.e. tem a ver com a condução concreta da vida, pois permite viver bem a vida;

3) A ética reside num elemento essencial, a virtude (os valores morais, no geral), na medida em que a virtude é o meio para a felicidade, que é o fim; ser ético é ser virtuoso e isso é o suficiente e necessário para ser feliz. Segundo Aristóteles, a virtude é um estado habitual que dirige a decisão, estabelecendo-se uma relação útil entre virtude e sabedoria para sermos virtuosos (Aristóteles, 1992: 1103b26-28; Santos, 2012: 17).

Relativamente a 1), a retórica aristotélica tornou-se uma técnica total; integra uma ética que não coloca a eficácia em primeiro plano, segundo Philippe Breton (2002: 68). Com a adaptação ou transformação da palavra em técnica para persuadir, a linguagem passou por um processo de tecnicização e de omnipotência retórica. O uso desta técnica 
retórica (tekhné rhétoriké), todavia, deve ser relacionado com uma ética específica, segundo Breton: "a tecnicização da palavra pode, de facto, basear-se, a montante, numa ética e ao mesmo tempo na busca de eficácia, ou estribar-se, a jusante, na busca da pura eficácia à custa do que quer que seja" (2002: 69). As mensagens publicitárias são, neste sentido, o produto da técnica retórica, recorrendo ao texto e à imagem para se tornarem esteticamente mais apelativas e críveis (Grunig, 1990: 8).

Quanto a 2), a ética não é a moral. Enquanto a ética é uma reflexão crítica sobre a moral e tem origem na interioridade, na autonomia do indivíduo, a moral tem origem na exterioridade, na vivência dos costumes quotidianos: "a moral diz respeito às acções praticadas por hábito e aos costumes em geral, o que privilegia o lado pelo qual a acção é ainda exterior ao sujeito" (Renaud \& Renaud, 1999: 960). A publicidade pode ser amoral ou moral/imoral. A publicidade e a moral são duas esferas distintas. Na actividade criativa da publicidade não é pensável, como na ciência, uma neutralidade moral. A criatividade determina que a publicidade, enquanto actividade artística, não depende da moral, i.e., é amoral. Todavia, pode revestir-se de moralidade ou imoralidade. Existe publicidade com sentido moral, preocupações éticas, ensinamentos práticos, mas também publicidade imoral.

Sobre o ponto 3) há uma proximidade entre ser ético ou virtuoso e ser feliz, apesar de se separar, por vezes, estes dois estados de virtude e de felicidade. Esta separação é, em determinadas culturas, uma clivagem não necessária entre seguir a virtude e a lei, desistindo-se de ser feliz, e a procura do prazer e do sucesso, em detrimento de ser virtuoso. Segundo João César das Neves (2008: 20), no primeiro caso, pode-se conseguir bens de eficiência e de eficácia (o sucesso produtivo e profissional), no segundo caso, pode-se conseguir bens de excelência (uma vida plena e com sentido) ou a aretê para a Antiguidade Clássica grega, "a qualidade pela qual algo ou alguém se mostra excelente" (Barroso, 2008: 65). Não é pelo primeiro caso que se é ético; é pelo segundo caso. Por conseguinte, a ética só tem sentido se aplicada às questões quotidianas da vida prática, i.e. como phronêsis (sabedoria prática), pois saber o que é a ética não é suficiente se esta não se exercer na prática e nos tornar éticos. A utilidade da ética está na ética ser phronêsis.

O problema-chave é, de facto, o que saber e o que fazer para nos tornarmos éticos numa determinada actividade, como a publicidade. O caso da publicidade é deveras interessante para a aplicação da ética, porque a publicidade é uma estratégia e uma técnica de comunicação que, como tal, se apresenta num discurso constituído por uma estrutura complexa, associando texto (significantes verbais) e imagem (significantes icónicos) para construir mensagens persuasivas reportadas a um mundo idílico. A publicidade hiperboliza-se quando se propõe solucionar todos os problemas das pessoas. Este é o factor da eficácia argumentativa da publicidade.

Em De Officiis, Cícero demonstrou não concordar com a mencionada clivagem entre a virtude e a felicidade, tendo aconselhado: "A todos os que se propõem ter uma boa carreira, a filosofia moral é indispensável". Quatro questões estão subordinadas à proposição de Cícero: 
a) A razão ("ter uma boa carreira") com que se recomenda a ética é ética?

b) A ética tem lugar, por exemplo, no mundo da publicidade ou dos negócios?

c) O que fazer quando ser ético prejudica a carreira ou os negócios?

d) Para que serve a ética dos media?

Ad primun, é óbvio que para se conseguir uma boa carreira deve-se aprender o ofício (e.g. Publicidade, Relações Públicas, Jornalismo, Contabilidade, Finanças, Gestão, Economia, etc.). Por conseguinte, a razão alegada por Cícero para recomendar a ética não é ética (Neves, 2008: 7), porque "ter uma boa carreira" não tem a ver com a ética. É absurdo pensar que ser ético serve para se ter sucesso profissional, porque existem naturalmente outras vias mais directas, eficazes e menos éticas para se ter o sucesso pretendido.

Ad secundum, a questão de existir lugar para a ética no mundo da publicidade ou dos negócios é complexa, porque a ética deverá ter lugar, a priori, em todas as dimensões da vida humana. Ser ético é ser naturalmente humano, pois "a ética é a construção de uma vida, aquela construção que fazemos quer queiramos quer não" (Neves, 2008: 9). Ser ético não implica desistir do sucesso nos negócios; é independente de ter uma boa carreira. Todavia, entre ser ético e ter uma boa carreira e não ser ético e ter, na mesma, uma boa carreira, é claramente preferível a primeira situação. A ética favorece, de um modo geral, ter uma boa carreira, na perspectiva de Cícero. A fundamentação da ética é indiscutível, porque "a ética não trata do mundo; a ética tem que ser uma condição do mundo, como a lógica" (Wittgenstein, 1979: 77; 1999: \6.421).

Ad tertium, quando ser ético prejudica a carreira ou os negócios, saber o que fazer significa saber qual é a coisa certa a fazer numa dada situação em que se está envolvido. Nesta perspectiva, ter pruridos éticos e preocupações morais não só não conduz como dificulta a obtenção de sucesso. Possuir bens de excelência dificulta conseguir bens de eficiência e de eficácia.

Ad quartum, os meios de comunicação social cumprem o designado serviço público, por um lado, mas não podem deixar de ser empresas rentáveis economicamente (Camps, 1996b: 145). "Os meios de comunicação não são agrupamentos altruístas sem fim lucrativo como as ONG. São empresas com a sã intenção de cobrir os gastos e beneficiar de ganâncias económicas", ou seja, maximizar os benefícios como o objectivo de qualquer outra empresa (Camps, 1996b: 153). Segundo João César das Neves: "Na ética não se trata de determinar o comportamento ideal, o gestor perfeito, a atitude impoluta. Isso é uma ficção, cuja utilidade costuma a ser muito duvidosa. Somos seres humanos, não anjos. [...] A ética é apenas a tentativa de ser bom" (Neves, 2008: 10). Os media também são sobressaltados por preocupações éticas. Principalmente numa sociedade de consumo que produz em excesso e tem de vender tudo o que produz. A produção em massa cria a necessidade de provocar o consumo em massa, mesmo que os produtos sejam inúteis, supérfluos e sem qualidade. Para provocar esse consumo em massa, existe a publicidade e o marketing, por exemplo, enquanto técnicas de comunicação persuasiva.

O tema da ética é, sic et simpliciter, racional, dialéctico e reflexivo. As questões éticas são, por norma, aporéticas. Assim, este texto privilegia uma análise crítica da ética 
na publicidade e na comunicação. A metodologia traduz-se na problematização e conceptualização da ética da publicidade como uma estética do discurso retórico.

\section{2. ÉTICA E RETÓRICA DA PUBLICIDADE}

A publicidade é uma técnica de comunicação estratégica. A aplicação eficaz desta técnica pretende a produção e exploração de certas conotações em mensagens persuasivas. Trata-se de uma técnica retórica, pois, conforme esclareceu Górgias, a retórica é a arte dos discursos, o bem supremo que dá a quem a possui a liberdade para si próprio e domínio sobre os outros, ou seja, "o poder de persuadir pelo discurso" qualquer pessoa (Platão, 1999: 452e). De um modo geral, a retórica é "a capacidade de descobrir o que é adequado a cada caso com o fim de persuadir" (Aristóteles, 1998: 1355b). Tal como na Antiguidade Clássica, a estrutura social das sociedades actuais e complexas assenta no paralelismo entre antigo e moderno ou tradição e modernidade. Este paralelismo contribui para a ressemantização ou reconversão do "antigo", conforme admitiu Roland Barthes acerca da designada "retórica antiga" face ao moderno, ao afirmar que "o mundo está incrivelmente cheio de Retórica antiga" (Barthes, 1987: 19). A essência da publicidade é desde sempre chamar a atenção, suscitar o interesse, despertar o desejo, permitir a memorização, conduzir à acção e à repetição da acção. A publicidade torna-se, por isso, uma técnica retórica antiga e moderna.

Não estará o mundo moderno, como disse Roland Barthes, cheio de retórica antiga? Hoje, as sociedades são mais hedonistas; há mais distracções; é mais difícil levar uma vida contemplativa e auto-reflexiva; existe uma maior percepção sobre a velocidade das vivências e sobre a escassez do tempo; é cada vez mais visível a diluição entre o "eu privado" e o "eu público"; prolifera a iconolatria no espaço público e a cultura do ecrã, etc. Por tudo isto se torna necessário reflectir, interpretar e problematizar a edificação desta cultura visual ou "civilização da imagem", segundo Gilles Deleuze. Esta civilização é uma "civilização do cliché", para a qual contribui a publicidade enquanto retórica moderna sofisticada. Os conteúdos e formas da publicidade, os produtos e marcas anunciados, as estratégias e a proliferação dos discursos são reproduções sociais desta civilização. A publicidade representa o que uma dada cultura valoriza e consome, ou seja, revela o que é: a homogeneização dos valores sociais e princípios morais, estilos de vida, necessidades e desejos.

De acordo com Chaïm Perelman, "a teoria da argumentação [...] abrange todo o campo do discurso que visa convencer ou persuadir, seja qual for o auditório ao qual se dirija e seja qual for o assunto sobre o qual incida" (Perelman, 1977: 19). Em A Aventura Semiológica, Roland Barthes definiu a retórica como uma metalinguagem, cuja linguagem-objecto é o discurso. A retórica, tal como a poética, é um discurso sobre o discurso. Ambas comportam várias práticas, como uma técnica ou arte da persuasão, um ensino, uma ciência ou proto-ciência, uma moral e uma prática social (Barthes, 1987: 20).

Se a publicidade explora as potencialidades do discurso para se tornar eficaz, é uma forma de retórica ou arte do discurso persuasivo. Falar em retórica da publicidade pressupõe o cuidado ético no uso desta técnica de comunicação, pois os fins estão 
determinados e não justificam os meios. Neste sentido, impõe-se falar da ética ou da ética aplicada à publicidade.

A publicidade assume uma dimensão retórica por ser uma arte e uma técnica: arte pela estética ou embelezamento do discurso mais sedutor; técnica pela persuasão do discurso. A publicidade assume também uma dimensão ética devido às estratégias que utiliza para conseguir os fins pretendidos, havendo a possibilidade das estratégias serem ardilosas, falaciosas ou falazes.

O problema crucial é relacionar e reflectir sobre a ética e a retórica da publicidade. Entre as duas há uma correspondência e uma oposição. Há correspondência, porque ambas se implicam, pois não existem usos de linguagem publicitária sem estratégias retóricas de produção de sentido e assentimento nem intenções de respeitar a ética do discurso (também não existe ética sem formas linguísticas de a expressar publicamente). Há oposição, porque quer a retórica da publicidade quer a ética da publicidade encerram-se em domínios distintos: a retórica, no âmbito dos processos de produção do discurso com determinados fins, tendo em conta o logos (amplo campo da racionalidade e uso da palavra); a ética, no âmbito dos modos justos de exercer a praxis linguística, tendo em conta o êthos e o pathos (amplo campo de valores e princípios morais).

A retórica define estratégias de produção do discurso, pertence ao campo do dizível, dos meios para atingir fins; a ética, propriedade inerente ao homo politicus (que partiIha e vive em comunidade) pertencente ao campo do indizível. Ora, como reflectir sobre uma retórica da ética ou sobre a presença de princípios e valores morais na produção e no uso dos discursos públicos interesseiros e convenientes como são os publicitários?

No sistema tipológico aristotélico, as obras de retórica inserem-se na classificação das produtivas ou ciências poéticas (tendo como fim a produção de discursos) e as obras de ética enquadram-se na classificação das ciências práticas (de orientação da acção). Estas são, adoptando a perspectiva aristotélica, as coordenadas da publicidade, que possui um cariz estético (i.e. de embelezamento do discurso, incluindo o texto e a imagem) e preocupações relativas aos valores morais e sociais (uso de uma determinada racionalidade comunicativa).

O papel dos princípios e valores morais no uso público da palavra relaciona a retórica e a ética. A retórica nunca deixou de ser aplicada profissionalmente na sua essência, i.e. como arte do discurso. No que é atinente propriamente à retórica como arte do discurso, é relevante a observação de que a prática de injustiça está relacionada com a eloquência, por um lado, e com o carácter das pessoas e o poder de influenciar as outras nas decisões justas, por outro lado (Aristóteles, 1998: 1372b).

Nas mensagens publicitárias está presente o dever de recorrer a argumentos que "não podem" ser recusados, porque se impõem aos destinatários de forma reconhecível e aceitável. Os argumentos são publicitados com o fito de irrefutabilidade. A concepção do discurso publicitário como um artefacto retórico (i.e. significativo, transmissível, racional e dirigido a um auditório determinado) apoia-se na perspectiva retórica de um orador que procura convencer. Estes procedimentos obedecem ou não a princípios morais que regulam o uso da palavra? Devem ou não ser pautados por normas éticas? 
A pertinência em relacionar a retórica e a ética reside em considerar que a ideia de verdade escapa, por vezes, aos princípios que presidem à produção dos discursos publicitários. Apesar de a argumentação pender para a arte de produção do discurso retórico ou para os princípios e valores de verdade e justiça, as mensagens publicitárias desviam-se desta orientação de um modo natural, dadas as especificidades destas mensagens que todos reconhecem como opostas à informação verdadeira. A retórica publicitária estará, deste modo, em oposição aos ideais éticos da verdade, porque negligencia as normas e procedimentos que conduzem ao bom uso da argumentação, isto é, ao uso justo e correcto da retórica para persuadir.

A linguagem publicitária funciona como objecto de consumo. Por exemplo, "A razão movida pela escolha" (Fiat) é um slogan paradoxal pela inversão entre "razão" e "escolha" mediada pela palavra "movida". O objectivo não é dizer a verdade; é persuadir. $O$ processo de persuasão confunde intencionalmente a significação. Os anúncios geram significados pela confusão estratégica. Colocam-se questões éticas face ao papel e às influências sociais da publicidade, principalmente numa época do triunfo do espectáculo, do liberalismo do mercado global ou, conforme referiu Giorgio Agamben, qualquer outro nome que se queira dar ao processo que domina hoje a história mundial, como a "alienação da própria linguagem, da própria natureza linguística e comunicativa do homem, do logos" (Agamben, 1993: 62).

Este repto de Agamben serve de advertência face à emergente sociedade do espectáculo. Uma época global em que a comunicação surge como ideologia da modernidade, cujas consequências mais evidentes são a crise de valores e a perda de humanidade, sociabilidade e, paradoxalmente, comunicabilidade. Conforme acrescentou Agamben, "o que impede a comunicação é a própria comunicabilidade, os homens estão separados por aquilo que os une" (Agamben, 1993: 64). Há uma espécie de alienação da natureza linguística do homem, para a qual também a publicidade contribui.

Esta alienação ou desenraizamento do ser linguístico ou do novo homo comunicans deve-se, em parte, a esta época de excessos de comunicação e de pretensos conhecimentos. Segundo Victoria Camps, os actuais sistemas político-sociais são convertidos em "mediacracias" dominadas por uma nova elite do "fast culture" e do "fast thinking" ou ready-to-think (Nietzsche, 1998: 228). Uma elite especializada na fabricação de consentimentos e de consensos, conforme já tinha advertido, em 1922, Walter Lippmann (2004: 134).

\section{3. ÉTICA DA COMUNICAÇÃo}

Um dos campos mais interessantes da ética contemporânea cinge-se na objectividade ou pluralidade pós-metafísica, designadamente na comunicação verbal ou interacção discursiva. Neste campo, pretende-se a objectivação da ética, extensível a todas as dimensões da natureza, incluindo todas as formas de vida e o próprio meio-ambiente.

O foco da ética transferiu-se, passou da subjectividade da natureza humana para a interiorização da razão, através da auto-consciência humana cumpridora da norma 
gerada por si mesma. Esta auto-consciência ética remonta à Antiguidade Clássica grega, como se disse anteriormente com a ética aristotélica sobre aquilo que é estimado como bom (eudaimon) e culminou na ética solipsista, monológica e intimista de Kant, na qual o indivíduo impõe a si mesmo a norma de conduta que deve ser tal que esta possa tornar-se norma universal, isto é, válida para todos. Com Kant, a ética deontológica da norma moral incide sobre aquilo que se impõe como obrigatório, a "boa vontade" (Kant, 1992: 21).

A mencionada transferência ética deve-se à modernidade e à secularização da vida (e.g. a perda dos valores morais) que superou o modelo metafísico (cósmico) e teológico (baseada em princípios divinos) e que instaurou a razão como o único fundamento da ética (baseada em princípios da liberdade auto-legisladora). As normas éticas deixaram de ser natural e teologicamente heterónomas e passaram a ser racionalmente autónomas, ou seja, impostas pela própria razão a si mesma, conforme defendeu Kant com o conceito de "boa vontade" na fundamentação do imperativo categórico como norma da moralidade.

Depois das éticas de Aristóteles e de Kant, um novo género de ética se impõe como sabedoria prática (phronêsis), pelo que uma outra transferência de foco do campo ético verifica-se com a transição de um modelo ético mentalista (em que a consciência ou a razão é o centro dos princípios que devem orientar a acção moral - o sujeito moral é um sujeito consciente) para um modelo ético linguístico (em que aprender a usar as palavras conduz a uma forma de pensar, agir e organizar o mundo), que agora interessa abordar com mais destaque no presente texto, porque a transição ética efectua-se a partir da consciência individual para a intersubjectividade e interacção comunicativa. Este modelo ético linguístico preconiza a ideia de que através das palavras fazemos a interpretação das coisas, comunicamos e entendemos a realidade.

A linguagem não serve apenas para expressar pensamentos ou sentimentos, mas também para agir socialmente, se bem que comunicar é já per se interagir, produzir acções. Comunicar é uma forma de agir e a publicidade, enquanto técnica retórica de comunicação, representa exponencialmente esta exigência ética por via da sua finalidade em persuadir para vender, i.e., usar a comunicação como meio para atingir um fim: vender o produto ou a marca. A técnica retórica torna-se uma ferramenta poderosa para colonizar os espíritos dos públicos, estando muito longe dos ideais antigos da sua génese republicana, pois, é este o sentido da expressão de Nietzsche da retórica como "arte essencialmente republicana" (Nietzsche, 1995: 27).

Como técnica de comunicação, a publicidade informa sem ser esta a sua finalidade. A informação é um meio do processo de influência ou persuasão, não é um fim da publicidade. O propósito da publicidade é persuadir para vender, "influenciar para provocar um comportamento de compra" (Breton, 2002: 59). Por vezes, cria necessidades e desejos espúrios nas pessoas, fomentando uma sociedade cada vez mais pós-moderna ou secular, hedonista e consumista. A publicidade "modela as consciências", na medida em que "veicula por si própria a apologia da sociedade de consumo e da cultura de massas" (Breton, 2002: 60). A publicidade pode basear-se numa dada sensibilidade 
dominante na cultura em que se insere para tornar mais eficaz a mensagem que divulga. Por exemplo, o conceito de "portugalidade" explorado pela publicidade às marcas Sagres e Azeite Gallo.

Todavia, mais do que uma técnica de comunicação comercial, a publicidade afirma-se, cada vez mais, como uma amostra dos valores morais de uma determinada cultura ou sociedade. Esta circunstância coloca a publicidade sob um escrutínio ético rigoroso e cauteloso.

O princípio de universalidade ética é baseado numa perspectiva pragmática universal com exigências de consenso, ou seja, actuante sobre todos os participantes, ou seja, todos para quem a norma possui valor ético. Jürgen Habermas desenvolveu esta ideia de razão prática universal no campo de uma teoria da comunicação que o próprio autor designou por teoria da acção comunicativa. Esta acção é social. O bem e a justiça são dois valores complementares e ambos exercem um papel activo na vida. É a comunicação que inter-relaciona os indivíduos e se constitui o elo entre a racionalidade universal (eticidade) e a vida quotidiana (contextualização).

As técnicas retóricas modernas, como a publicidade, edificaram uma nova elite no lado da produção e da emissão de discursos, formando uma "mediacracia". Se juntarmos a esta concepção o que, por exemplo, Habermas referiu em A Teoria da Aç̧ão Comunicativa ao denunciar a colonização económica, política e social de que é alvo a nossa vida, torna-se emergente, seguindo o repto de Habermas, recusar e resistir à colonização, de modo a preservar a vida humana da contaminação.

A questão comunicacional (ou o chamado paradigma comunicacional) marca a modernidade e tem sido emergente. Primeiro, porque se reveste de interesse, numa época de transformações tecnológicas; segundo, porque implica, como sempre, a comunicação como condição básica da vida social. De acordo com Habermas, a partir da comunicação "se constituem as ordens de legitimidade que regulam as relações sociais, o saber disponível nas interacções e o processo de socialização que gera as identidades individuais" (Habermas apud Esteves, 2003: 40).

Habermas distinguiu a acção comunicativa e o uso estratégico da linguagem, baseando-se na procura (i.e. na acção estratégica) dos interlocutores por entendimento e influência (Habermas, 1984c: 181-183). A acção estratégica é aquela em que um falante usa, através de um enunciado, o seu interlocutor como um meio para realizar um determinado interesse (e não apenas para comunicar). Para Habermas, "só há acção comunicativa quando a interacção está voltada para o entendimento válido e os participantes do diálogo harmonizam sem reservas os seus fins ilocucionários" e obtêm consensos (Magalhães, 2010: 155).

Esta é uma teoria global da acção social, em que o agir situa-se no quadro de uma interacção que se constitui na base de regras alicerçadas na comunicação. Por isso Habermas se interessou pelos modelos universais do agir que estruturam a comunicação linguística como um conjunto de dizer e de fazer (i.e. os universais pragmáticos). Há um carácter duplo da comunicação: a) a comunicação é dirigida à produção de convenções para o consenso; b) a interiorização de formas ideológicas codificadas provoca no sujeito formas comunicativas sistematicamente distorcidas (Habermas, 2003: 24; 1984b: 
278). Deste modo, é no quadro das relações de comunicação que se devem apreender os pressupostos gerais para a racionalidade e a verdade, de modo a distinguir a comunicação distorcida da comunicação autêntica. A publicidade encontra-se no cerne desta questão ética por via de se constituir uma técnica retórica para persuadir e uma actividade prática para vender, independentemente dos meios e estratégias que utiliza.

A acção comunicativa é orientada para a compreensão e é eminentemente uma acção social. Habermas definiu a sociedade na base de actos de comunicação que são racionais e vinculam os interlocutores. Estes actos são dirigidos tendo em conta um acordo ou sucesso (Sfez, 1995: 12). A comunicação está, por conseguinte, no cerne dos vínculos sociais. Dados estes pressupostos, realizam-se processos de entendimento e visam-se acções resultantes de preferências e interesses (Habermas, 2010b: 21).

A teoria da comunicação de Habermas pressupõe a ética do discurso e a razão prática universal. A intenção de Habermas foi a de construir uma perspectiva moral que formasse um juízo ou princípio ético imparcial e universal, sem ser uma espécie de imperativo único como propôs Kant. Este juízo ou princípio ético seria um ponto de referência ou parâmetro de observação para avaliar, julgar e discutir a validade das normas morais (Rasmussen, 1991: 60-62).

Ao contrário de Kant, que propôs um princípio de acção universal a partir do próprio sujeito que impõe a todos uma máxima que pretende tornar lei universal, Habermas sugeriu que o sujeito submetesse a sua máxima a todas as outras pessoas para que se examine e se discuta a sua pretensão de universalidade (Pegoraro, 2006: 146). Do formalismo kantiano que prescreve que se deve agir de tal modo que a sua acção se torne máxima universal desloca-se para o formalismo linguístico habermasiano que prescreve que o sujeito propõe para análise, discussão e validação uma norma individual contestada que deve tornar-se universal e consensual.

A ética do discurso de Habermas é uma ética de procedimentos formais, para a "formulação de um princípio universal de justificação ou validação das normas morais" (Pegoraro, 2006: 139). O princípio seria universal devido à linguagem, que transcende os limites de uma época e de uma cultura. É uma ética dialógica, porque privilegia o entendimento e consenso entre interlocutores por mediação da linguagem e da racionalidade discursiva por referência à verdade, bem como considerando o contexto das interacções mediatizadas pela linguagem. Habermas pretendeu dirimir eventuais conflitos argumentativos entre interlocutores e apresentar bases para uma regulação conciliadora da conduta e da prática social. As normas morais existentes e em conflito podem ser convertidas em normas válidas e aceites por todos, ou seja, a construção argumentativa de um consenso universal. Neste sentido, trata-se também de uma ética processual (realiza-se enquanto tal) e construtiva (é construída pelos próprios participantes para solucionar conflitos e criar consensos), pelo que é completamente desajustada face ao campo de intervenção e influência dos discursos publicitários.

A ética de Habermas é concebida sobre o discurso. Este discurso tem de ser, por seu turno, verdadeiro ou, pelo menos, com pretensão de enunciar a verdade. Por conseguinte, a linguagem comporta sempre duas condições fundamentais: i) racionalidade e ii) referência à verdade. Os discursos publicitários não seguem estas duas condições 
fundamentais nem devem, pois afastavam-se da sua essência se o fizessem, visto que pretendem exclusivamente persuadir para vender.

A publicidade não pode assumir o compromisso de procedimento proposto pela pragmática universal, pois não justifica a racionalidade comunicativa com pretensões de validade na ética discursiva. A ética discursiva encontra-se sempre assente sobre a realidade, porque é o resultado de um universal pragmático construído com a participação de todos os agentes morais que são o produto de uma cultura onde vive e pertence.

As sociedades contemporâneas são, cada vez mais, dominadas por uma lógica da razão instrumental, de interesses e discussões sobre questões práticas de natureza estratégica, em que se tenta persuadir através de procedimentos retóricos falaciosos e favoráveis, independentemente de critérios de verdade ou validade, omitindo-se factos que contrariam a argumentação. Verificam-se estas estratégias de comunicação nos campos da publicidade ou do marketing, totalmente desinteressadas e afastadas do que é a verdade, a validade e a racionalidade comunicativa.

Nestes casos, como aplicar ou seguir uma ética da discussão se esta se apresentar prejudicial e contrária à estratégia persuasiva que se pretende? Não seria possível, porque a ética da discussão é deliberadamente contrafactual (Santos, 2012: 260). É indiferente à intenção, mesmo que esta seja boa, pelo que se alguém afirmar algo contrário aos princípios de validade da racionalidade comunicativa, sem se respeitar as regras do jogo argumentativo, este não se invalida nem entra em colapso.

\section{SeCularização da publicidade}

$\mathrm{Na}$ publicidade subliminar, certas mensagens com influência indirecta e imperceptível no público são ocultadas numa outra considerada inocente, casual e fugaz. $\mathrm{O}$ exemplo mais recente foi a mensagem publicitária da Samsung num momento de aparente casualidade, como o registo de uma auto-fotografia de grupo (selfie) por Ellen DeGeneres na entrega dos óscares de Hollywood, evento transmitido em directo para todo o mundo. A actriz registou o momento com um telemóvel da Samsung conforme um acordo publicitário com a $A B C$. Não se tratou de uma acção espontânea, como fazia parecer, mas de uma estratégia publicitária para a Samsung, um product placement mascarado de inocência e espontaneidade.

A manipulação no campo dos media é um sério problema de ética que, por se tratar de meios de comunicação social, provocam repercussões em larga escala. Veja-se o exemplo da "publicidade sem fronteiras", conforme a designa Gilles Lipovetsky (1989: 247), que não pára de invadir novos espaços e assumir novas e artísticas roupagens da arte e do cinema, cada vez mais visíveis e influentes. "Se é verdade, como diz Séguéla, que a 'verdadeira' publicidade alinha pelos métodos do star-system, é ainda mais verdadeira a afirmação de que ela é uma comunicação estruturada como a moda, cada vez mais sob a dependência do espectacular, da personificação das aparências, da sedução pura" (Lipovetsky, 1989: 251).

A publicidade não se exerce apenas no campo do consumo, mas também suscita tomadas de consciência perante problemas, levando à modificação de comportamentos, 
como no caso do alcoolismo, droga, prevenção rodoviária, etc. A publicidade sensibiliza, reorienta certas atitudes e comportamentos morais. Todavia, não é uma manifestação totalitária ou doutrinária (Lipovetsky, 1989: 260). A publicidade "influencia mas não ameaça, sugere mas sem pretender a dominação doutrinal, funciona sem maniqueísmos nem culpabilização" (Lipovetsky, 1989: 260). Difunde normas e ideais, mas pouco praticados. "A publicidade não se encarrega da redefinição completa do género humano, explora o que está em embrião tornando-o mais atractivo para mais indivíduos" (Lipovetsky, 1989: 261).

É um dado adquirido que as mensagens publicitárias exercem um poder de alcance e um poder de persuasão. O exercício desses poderes exige uma reflexão ética sobre os seus efeitos. Esta reflexão nem sempre é realizada, porque se submete à lógica do mercado. Mesmo assim, a actividade publicitária não tem a incumbência de pautar a moralidade ou a ideologia, redefinir os valores sociais e padrões culturais ou reformar a própria natureza humana. Se existe um poder, existe forçosamente um alvo e um impacto.

Um sinal de secularização reside nos meios utilizados para convencer, que dependem dos valores dominantes na sociedade em que são usados. Segundo Victoria Camps, "a secularização privatizou ou individualizou tudo", na medida em que "tudo é relativo, incluindo aqueles valores que a nossa cultura e a nossa tradição conceberam como universais" (Camps, 1996b: 61). Deste modo, vivemos numa certa confusão, em que os próprios valores morais se tornam relativos, subjectivos e cada vez menos críveis.

Viver num regime democrático e numa sociedade da informação significa, paradoxalmente, a existência de mais liberdades, mais tratamento e difusão de informação, mais pluralidade de meios de comunicação e de mensagens mass-mediáticas e mais transparência na actuação dos media, mas também mais estratégias de manipulação de consciência.

Todavia, o poder da publicidade é relativo, porque "a publicidade só tem acção eficaz sobre o acessório e o indiferente" (Lipovetsky, 1989: 261). Segundo Lipovetsky, atendendo à superficialidade das suas mensagens, "a própria publicidade não passa de um poder de superfície, uma espécie de grau zero do poder, a partir do momento em que é medida pela bitola das existências individuais" (1989: 261).

A publicidade não aniquila o espaço público da discussão e da crítica, mas pode amplificar pseudo-valores, lançar em circulação certas referências e celebridades, tornando igual o superficial e o profundo, uniformizando desejos, usos, gostos, modas. A publicidade possui o poder estratégico de redefinir estilos de vida centrados naquilo que promove: o consumo. "A publicidade contribuiu para desclassificar a ética da poupança em proveito da ética do dispêndio e da fruição imediata" (Lipovetsky, 1989: 264). A publicidade insemina uma cultura hedonista e assume-se um agente de individualização, acelerando a busca de personalidade e de novas formas de expressão.

Numa obra intitulada A L'Ombre des Majorités Silencieuses - La Fin du Social, Jean Baudrillard identificou esta exigência colectiva de novas formas de expressão, culminando no fim ou morte do social (o vazio social) e, por contraposição, no apogeu das 
massas: "as massas resistem escandalosamente a esse imperativo da comunicação racional. Atribuímos-lhe sentido e elas querem espectáculo. Nenhum esforço é capaz de as converter à seriedade dos conteúdos" (Baudrillard, 1982: 15).

\section{ConClusão}

Como é possível denunciar a mentira persuasiva e paga, que é própria das mensagens publicitárias? Seria absurdo normalizar uma prática generalizada e caracteristicamente enraizada na mentira, insinuação, manipulação, excesso ou exagero, omissão, distorção e ataque à concorrência. Os meios e os fins, a mentira e a verdade, o bem e o mal, o justo e o injusto, informação e publicidade comercial ou propaganda ideológica, imagem e voyeurismo, público e privado pertencem ao mesmo campo do problema e são práticas sociais híbridas.

Um exemplo do constante surgimento ou aprimoramento de estratégias ardilosas e novas formas insidiosas de abuso do poder mediático é a "publi-reportagem", uma hibridez perniciosa que é sempre, no fundo, alguma publicidade, mas não respeita a imparcialidade e objectividade dos critérios de noticiabilidade jornalística. Neste caso, a obrigação e necessidade de vender cria sensacionalismo e grandes títulos enganadores.

Charles Taylor caracterizou este novo paradigma ético. Em A Ética da Autenticidade, apresentou três doenças da modernidade: i) o individualismo e perda do colectivismo; ii) o predomínio da razão instrumental sobre a razão crítica; iii) a diminuição da participação política ou abstencionismo (Taylor, 2009: 19-24). Estas três maleitas da modernidade fomentam uma cultura pós-moderna do narcisismo conformista e dependente. A fonte da moralidade está dentro do sujeito e permite-o distinguir intuitivamente o bem do mal.

Em Paradoxos do Individualismo, Victoria Camps refere-se a uma sociedade de incomunicados, apesar de a comunicação ser o paradigma cultural do século XX e de a técnica tornar muito simples comunicar: "A possibilidade de comunicarmos é um valor do nosso século, um valor que muito provavelmente ocupou o lugar dos valores ilustrados do progresso e a razão." (Camps, 1996a: 143). "A sociedade da comunicação não é mais solidária nem mais afectiva" (Camps, 1996a: 21). Se os media, paradoxalmente, "não nos fazem comunicar, contribuindo antes para nos isolar no nosso próprio mundo", conforme afirmou Victoria Camps (1996a: 21), a questão da ética surge ao indagar se os media devem servir para aquilo que estão a servir.

A pós-modernidade é apanágio das sociedades ocidentais de cariz capitalista, nas quais se regista uma evidência nas mudanças de comportamentos nas massas populares a partir da década de 1980. O conceito de "pós-modernidade", apresentado pela primeira vez por Jean-François Lyotard em 1979, com a obra A Condição Pós-Moderna, sustenta a descrença no paradigma da modernidade, que culmina na deslegitimação dos ideais, utopias, mega-narrativas, preceitos e imperativos do dever. Surge um outro paradigma neoliberal e amoral, o da massificação da produção e do consumo, o da industrialização e da tecnologia neo-liberal, o do individualismo indiferente e hedonismo neo-dionisíaco alimentado pelo espectáculo gratuito, sedução e prazer imediato. 
A publicidade manifesta-se em múltiplos campos da sociedade e está omnipresente, de uma maneira irrefragável, na vida quotidiana. Principalmente nas designadas culturas, sociedades e mercados de massa, onde o nível de produção e de consumo de bens materiais é gradualmente crescente. O público da publicidade é crédulo, irreflectido, sugestionável e impulsivo, pelo que o apelo a tendências e impulsos torna-se mais fácil. O público é impulsivo e adere facilmente à mensagem (Uceda, 2001). O discurso da publicidade é uma orto-doxia sobre desejos e sensações.

Na publicidade, os conteúdos e formas da linguagem são progressivamente sofisticados, recorrendo aos contributos da psicologia e da sociologia para influir nos comportamentos dos consumidores. O texto e a imagem são adaptados para possuírem a capacidade de influenciar o inconsciente humano e estimular desejos, além de serem "portadores de mensagens culturais que determinam condutas aos indivíduos expostos" (Veríssimo, 2008: 18). O público compra o produto, mas consome o signo, como advertiu Baudrillard. Este signo assenta na imagem de marca do produto adquirido e é a imagem que os consumidores querem manifestar de si próprios. A publicidade apresenta imagens positivas da vida através de um discurso optimista, sedutor, sensual, atractivo, com sensações de agrado e prazer, modelos ideais e estereótipos sociais a seguir e a imitar como se tratasse de uma fantasia colectiva em que se acredita. Segundo Baudrillard, "o aspecto actualmente mais interessante da publicidade é o seu desaparecimento, a sua diluição como forma específica, ou como medium, muito simplesmente. Já não é (alguma vez foi?) um meio de comunicação ou de informação. [...] Se num dado momento a mercadoria era a sua própria publicidade (não havia outra), hoje a publicidade tornou-se a sua própria mercadoria" (Baudrillard, 1991: 116).

O desaparecimento da publicidade justifica-se pela sua diluição enquanto forma específica de comunicação ou medium, como seria ou deveria ser. Baudrillard defende que se verifica uma transição estrutural e essencial da publicidade, que passou de medium de comunicação e informação de mercadorias para mercadoria, ou seja, a publicidade tornar-se a sua própria mercadoria.

A publicidade confunde-se consigo própria, porque as estratégias a que recorre, e.g. o erotismo, constituem indicadores do que é a própria publicidade. A publicidade é um medium transformado na sua própria mensagem, i.e. em si próprio, narcisicamente. A publicidade é mercadoria e, por isso, sobre ela recaem as leis do mercado, como a de procurar a publicidade por ela própria ser o que é.

Assim, nesta perspectiva, já não tem sentido avaliar ou acreditar na própria publicidade, porque a mensagem deixou de ter um conteúdo exterior a transmitir para ser ela própria uma mensagem incrédula, ideológica e produto capitalista. A publicidade obedece à lógica social do consumo, sendo ela mesma um produto ou serviço de consumo.

O discurso publicitário é sempre o resultado de um acto de fala intencional que, antes de ser transmitido, foi alvo de um estudo aprofundado, um plano previamente definido, uma estratégia deliberada para o tornar mais persuasivo e capaz de influenciar os públicos-alvo. O discurso publicitário não é inocente. O objectivo fundamental de um anúncio não é apenas mostrar ou informar sobre um produto ou uma marca; é apresentar um motivo ou fundamento para comprar. 
Também Umberto Eco propôs um exame da comunicação publicitária em que o foco deve ser deslocado: "de um lado temos, como objecto de indagação, vastas configurações semânticas que começam a interessar-nos ao nível dos iconogramas; do outro lado, abrem-se-nos perspectivas para a elaboração de definições de uma possível retórica visual" (Eco, 2001: 156).

$\mathrm{Na}$ relação entre a retórica e a ideologia, o paralelismo imediato surge com uma outra relação entre a comunicação e a cultura, i.e. a comunicação está para a cultura como a retórica está para a ideologia. "A leitura de algumas mensagens publicitárias terá, portanto, dupla função: de um lado, indicar como se pode articular um mapa dos códigos publicitários; do outro, mostrar como a análise semiológica, no momento em que implica a consideração daquele Outro do universo dos signos que é o universo das ideologias, supera os limites 'formalistas' que parecem ser-lhe próprios e passa a contribuir para um discurso mais amplo que co-envolve (enquanto discurso semiológico correcto, e não enquanto superação do discurso semiológico) a situação de uma sociedade no seu complexo." (Eco, 2001: 157).

Para Umberto Eco, a técnica publicitária parece assente no pressuposto de que "um anúncio mais atrairá a atenção do espectador quanto mais violar as normas comunicacionais adquiridas (e subverter, destarte, um sistema de expectativas retóricas)" (Eco, 2001: 157). Seguindo vários códigos (iconográficos, de gosto e sensibilidade, retórico, etc.), a comunicação publicitária baseia-se na proposta de arquétipos do gosto que preenche expectativas em conformidade com uma sensibilidade corrente.

Segundo Umberto Eco, um publicitário responsável e dotado de ambições estéticas tentará sempre realizar o seu apelo através de soluções originais e que permitam reconhecimento de genialidade associado ao produto proposto, provocando a sensação de agrado, identidade e satisfação ao consumidor (Eco, 2001: 157). Está implícita a importância, para a publicidade, dos componentes emotivos e estéticos, nomeadamente as figuras de estilo ou de retórica, para a provocação de efeitos.

Um caso crítico de utilização de imagens publicitárias que suscitaram efeitos polémicos, choque e discussões éticas foi o de Oliviero Toscani, fotógrafo da marca United Colors of Benetton, entre 1982 e 2000 . Toscani explorou o conceito de "choque" de certos tabus (e.g. homossexualidade, racismo, sida, sexo, etc.) sem ter a ver com o produto (Breton, 2002: 60). Neste caso, a ética foi tida em conta ou ajudou a publicitar ou a vender o produto? Não, porque se verificou o oposto, o primado da retórica sobre a ética e a marca conseguiu o que pretendia: posicionamento e notoriedade.

\section{REFERÊNCIAS BIBLIOGRÁFICAS}

Agamben, Giorgio (1993) A Comunidade Que Vem. Lisboa: Editorial Presença.

Aristóteles (1992) Éthique de Nicomaque. Flammarion, Paris.

Aristóteles (1998) Retórica. Lisboa: Imprensa Nacional - Casa da Moeda.

Barthes, Roland (1987) A Aventura Semiológica. Lisboa: Edições 70. 
Barroso, Paulo, "A pedagogia ideal da aretê na morte de Sócrates", Revista Egitânia Sciencia. (3) Instituto Politécnico da Guarda, 2008, pp. 61-74.

Baudrillard, Jean (1982) A L'Ombre des Majorités Silencieuses - La Fin du Social. Paris: Éditions Denoël/ Gonthier.

Baudrillard, Jean (1991) Simulacros e Simulação. Lisboa: Relógio d’Água.

Breton, Philippe (2002) A Palavra Manipulada. Lisboa: Caminho.

Camps, Victoria (1996a) Paradoxos do Individualismo. Lisboa: Relógio D’Água.

Camps, Victoria (1996b) El Malestar en la Vida Pública. Barcelona: Grijalbo-Mondadori.

Eco, Umberto (2001b) A Estrutura Ausente. São Paulo: Editora Perspectiva.

Esteves, João Pissarra (2003) A Ética da Comunicação e os Media Modernos - Legitimidade e Poder nas Sociedades Complexas. Lisboa: Fundação Calouste Gulbenkian.

Grunig, Blanche (1990) Les Mots de la Publicité. Paris: CNRS.

Habermas, Jürgen (1984a) Communication and the Evolution of Society. Newcastle: Athenaeum Press.

Habermas, Jürgen (1984b) The Theory of Communicative Action (vol. 1: Reason and the Rationalization of Society). Boston: Beacon Press.

Habermas, Jürgen (1984C) The Theory of Communicative Action (vol. 2: Lifeworld and System: A Critique of Functionalist Reason). Boston: Beacon Press.

Habermas, Jürgen (2003) On The Pragmatics of Communication. Oxford: Basil Blackwell Publishing.

Habermas, Jürgen (2010a) O Discurso Filosófico da Modernidade. Lisboa: Texto Editores.

Habermas, Jürgen (2010b) Fundamentação Linguística da Sociologia. Lisboa: Edições 70.

Heidegger, Martin (1990a) “La question de la technique”, Essais et Conférences. Paris: Gallimard, pp. 9-48.

Heidegger, Martin (1990b) “Que veut dire 'penser’ ?”, Essais et Conférences. Paris: Gallimard, pp. 151-169.

Kant, Immanuel (1992) Fundamentação da Metafísica dos Costumes. Lisboa: Edições 70.

Lipovetsky, Gilles (1989) O Império do Efémero. Lisboa: Publicações Dom Quixote.

Lipovetsky, Gilles (2004) O Crepúsculo do Dever - A Ética Indolor dos Novos Tempos Democráticos. Lisboa: Publicações Dom Quixote.

Lippmann, Walter (2004) Public Opinion. New York: Dover Publications.

Lyotard, Jean-François (1989) A Condição Pós-Moderna. Lisboa: Gradiva.

Magalhães, João Baptista (2010) Horizontes da Ética: Para uma Cidadania Responsável. Lisboa: Edições Afrontamento.

Neves, João César das (2008) Introdução à Ética Empresarial. Cascais: Princípia.

Nietzsche, Friedrich (1995) Da Retórica. Lisboa: Vega. 
Nietzsche, Friedrich (1998) A Gaia Ciência. Lisboa: Relógio d’Água.

Pegoraro, Olinto (2006) Ética dos Maiores Mestres Através da História. Rio de Janeiro: Editorial Vozes.

Perelman, Chaïm (1977) L'Empire Rhétorique. Paris: Vrin.

Platão (1999) Górgias. Lisboa: Lisboa Editora.

Ramonet, Ignacio (2003) A Tirania da Comunicação. Porto: Campo das Letras.

Rasmussen, David M. (1991) Reading Habermas. Oxford: Basil Blackwell.

Renaud, Isabel \& Renaud, Michel (1999) “Moral” in: Logos - Enciclopédia Luso-Brasileira de Filosofia. (Vol. 3) Lisboa: Verbo, pp. 956-979.

Santos, José Manuel (2012) Introdução à Ética. Lisboa: Documenta.

Sfez, Lucien (1995) A Comunicação. Lisboa: Instituto Piaget.

Singer, Peter (2004) Um Só Mundo - A Ética da Globalização. Lisboa: Gradiva.

Singer, Peter (2006) Como Havemos de Viver? A Ética Numa Época de Individualismo. Lisboa: Dinalivro.

Taylor, Charles (2009) A Ética da Autenticidade. Lisboa: Edições 70.

Uceda, García (2001) Las Claves de la Publicidad. Madrid: Esic Editorial.

Veríssimo, Jorge (2008) O Corpo na Publicidade. Lisboa: Edições Colibri.

Wittgenstein, Ludwig (1979) Notebooks - 1914-1916. Oxford: Blackwell.

Wittgenstein, Ludwig (1996) Philosophical Investigations. Oxford: Blackwell.

Wittgenstein, Ludwig (1999) Tractatus Logico-Philosophicus. London: Routledge.

$* * *$

Recebido a 18-03-2014

Aceite a 09-05-2014 